\title{
Improving Seismic Images for the Pre-Salt Reservoirs when Updating Salt Stratified Velocity Models
}

Alexandre Maul (1,2)*; Marco Cetale (2); Cleverson Guizan (2); João B. Boechat (1); María González (3); Thiago Yamamoto $(\mathbf{1 , 2})$; Leonardo Teixeira (1,2); Rodrigo Pontes (1,2) \& Josué Fonseca (1). (1) - Petrobras; (2) - UFF; (3) - Emerson.

Copyright 2019, SBGf - Sociedade Brasileira de Geofísica

This paper was prepared for presentation during the $16^{\text {th }}$ International Congress of the Brazilian Geophysical Society held in Rio de Janeiro, Brazil, 19-22 August 2019.

Contents of this paper were reviewed by the Technical Committee of the $16^{\text {th }}$ International Congress of the Brazilian Geophysical Society and do not necessarily represent any position of the SBGf, its officers or members. Electronic reproduction or storage of any part of this paper for commercial purposes without the written consent of the Brazilian Geophysical Society is prohibited.

\begin{abstract}
In complex areas such as the Pre-Salt Section in the Santos Basin, Brazilian offshore to represent as feasible as possible the geology using seismic images is a big challenge. One of the main causes of the observed imaging problems is the evaporitic section considerations in terms of velocity for the migration purposes. Ones consider this section as having an almost constant value (close to $4,500 \mathrm{~m} / \mathrm{s}$ ) which represent the halite behavior, the most abundant mineral in this section. Other, over these models, perform the tomographic inversion updating to give to the velocity model all the mathematical necessity to build confident seismic images. We believe we need to build starting velocity models reflecting any existing geological features prior to apply the mentioned tomographic updating. In this sense, we proposed the insertion of the so-called stratifications inside the evaporitic section taking an adaptation of the modelbased seismic inversion. Having this new velocity model reflecting the stratification, we indicate the same tomographic update approach to add to the geological constrains the mathematical complementation. Finalizing, we performed the migration once again and compared the results.
\end{abstract}

\section{Introduction}

Ji et al. (2011) defended the idea that homogenous velocity for the salt section affects the images under the salt section. They cited the weakness and discontinuity in seismic reflection, diffractions-like events and misinterpretation as the main problems when considering those homogeneous models.

Jones \& Davison $(2013,2014)$ mention many difficulties for the seismic imaging near salt bodies, using the Santos Basin, Brazilian offshore as the main example. They cite the inaccurate interval velocity assumption or representation for the salt section as the probable cause of this difficulty. They also observe some features such as inter bedded layers (our stratifications), overlying layers (our so-called superior anhydrite or the Albian rafts presence) and salt flanks (encompassed within the HSD Hidden Stratified Domain as postulated by Maul et al., 2018b).
Jackson et al. (2015) emphasize the presence of "enigmatic structures" within the salt section in Santos Basin. In Mohriak et al. (2008) we found the first statement of the term "enigmatic reflectors" which we believe has the same meaning of the "enigmatic structures". These features are inter bedded layers is seismic terms, i.e. the stratifications caused by the mineral variation when they were formed during the evaporation process of brines.

Since 2015, several results related to the salt stratification modelling intending to enhance the Pre-Salt projects have been presented (Maul et al., 2015, Jardim et al., 2015, Meneguim et al., 2015). From the methodology development diverse application have took advantage when using this strategy of modelling those stratifications. The more promises applications are related to uncertainties (Maul et al., 2015; Jardim et al., 2015), geomechanics (Toríbio et al., 2017, Teixeira et al., 2018) and seismic migration (Gobatto et al., 2016, Fonseca et al., 2018, Maul et al., 2018a).

Related to seismic migration tasks, until the beginning of the years 2000, the evaporitic section in the Santos Basin, offshore Brazil, was usually considered as almost constant (interval velocity around $4,500 \mathrm{~m} / \mathrm{s}$ ), or over this applying some tomographic inversion operation in order to update the needed interval velocity observing gather alignment behaviors.

Even knowing the tomographic inversion help the entire migration process it is not a perfect solution for the velocity models updating (Guo \& Fagin, 2002). These authors emphasize the needed of incorporating a reasonable geological knowledge into any velocity modelling workflow. Potentially, the FWI (Full-Waveform Inversion) methodology can generate high-resolution velocity models (Vigh \& Starr 2008), and those models are currently indicated when using the RTM (Reverse Time Migration) technique. However, according to Vigh et al. (2009), one of the main challenge when using the FWI technics is to produce (or to reproduce) a good starting velocity model to be used to forecast seismic data with geological confidence regarding the subsurface geology, where it has been acquired.

In this paper, we present seismic images built adopting as input the interval velocity model generated through the stratification modelling. In this case, we updated the initial model (the stratified salt one) by using tomographic inversion and the chosen migration algorithm was the Kirchhoff one. 


\section{Method}

The methodology used in this project follows the stated one presented by Maul et al., 2015 and represented in a workflow first presented by González et al., 2016. This method/workflow allows the insertion of the salt stratification or the layered salt by using a seismic acoustic inversion approach as postulated by Meneguim et al. (2015). This gives to the section the needed heterogeneity, especially to generate the initial velocity model for the tomographic updating process, which precedes the chosen migration process.

To ensure the efficiency of the application methodology (i.e. to generate the stratified model) we performed the tomographic inversion process and the gather alignment panels. For this process we used as the initial interval velocity model both approaches: the standard one that consider an almost constant interval velocity model for the evaporitic section, and the stratified one generated by the acoustic seismic inversion process, as tested and presented in Gobatto et al. (2016), Fonseca et al. (2018) and Maul et al. (2018a).

\section{Results and Discussions}

The methodology used in this project follows the stated one in Maul et al. (2015) and represented in a workflow first presented by González et al. (2016). This method/workflow allows the insertion of the salt stratification or the layered salt, given to the section the needed heterogeneity, especially to generate the initial velocity model for the tomographic updating prior to the migration task.

To ensure the efficiency of the application methodology (i.e. to generate the stratified model) we updated the initial model using the tomographic inversion analyzing the gather alignment panels and the built seismic images.

Figure 1 shows few wells drilled in the Santos Basin emphasizing the stratification presence in all of them.

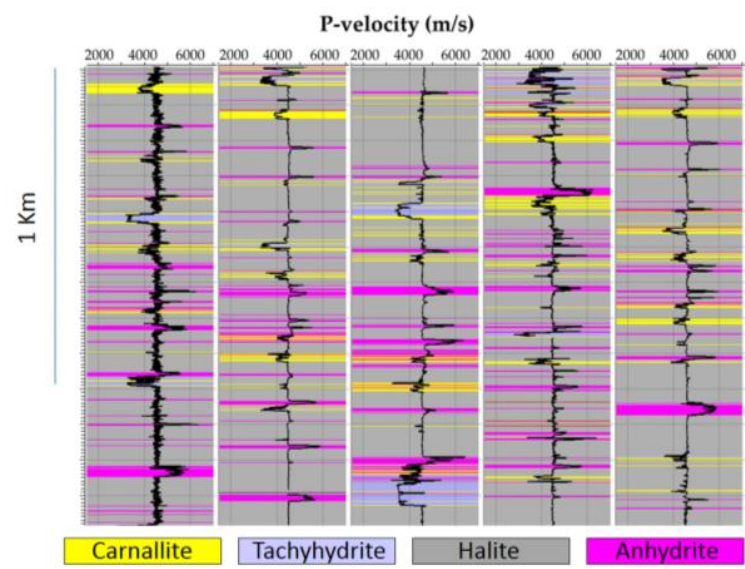

Figure 1: Identified stratifications inside the evaporitic section Adapted from Maul et al. (2018a).

The first thing we must consider when working with the heterogeneity inside the salt section is related to the mineral variation presence, their frequency and their property value variation. In this sense, Maul et al. (2018a) presented a table (Table 1) summarizing the study of almost 200 well drilled in Santos Basin reflecting the average behavior for each studied field, based on the grouping they used: Low Velocity Salt (LVS); Halite and High Velocity Salt (HVS).

Figure 2 illustrates, for a small piece of wells how the velocity can vary among the minerals. In this study, we considered the variation presented in this picture (in this case the average value per mineral).

Figure 3 illustrates how we represented the velocity model for the salt section considering the stratification insertion using the acoustic inversion approach.

Figure 4 illustrates the gather alignment panels allowing the comparison of both approach: to be using the standard way of tomographic updating of the salt flooded salt model $x$ the tomographic updating over the stratified salt model. It is important to mention the tomographic update in a mandatory task in both cases. The main difference when adopting the stratified model is to reduce the number of iterations during the inversion tomographic process without any reduction in terms of delivered data.

According to the images we can see in figure 5 , despite the gain related the computation cost, the image quality has also increased considering the image focusing, the structural representation, the vertical positioning/behavior, etc.

\begin{tabular}{|c|c|c|c|c|}
\hline Field & Wells & LVS & Halite & HVS \\
\hline 1 & 20 & $8 \%$ & $83 \%$ & $8 \%$ \\
\hline 2 & 29 & $9 \%$ & $82 \%$ & $9 \%$ \\
\hline 3 & 17 & $12 \%$ & $77 \%$ & $12 \%$ \\
\hline 4 & 3 & $13 \%$ & $71 \%$ & $16 \%$ \\
\hline 5 & 5 & $3 \%$ & $84 \%$ & $13 \%$ \\
\hline 6 & 7 & $3 \%$ & $80 \%$ & $17 \%$ \\
\hline 7 & 72 & $8 \%$ & $81 \%$ & $11 \%$ \\
\hline 8 & 25 & $4 \%$ & $88 \%$ & $8 \%$ \\
\hline 9 & 4 & $6 \%$ & $81 \%$ & $13 \%$ \\
\hline & $\mathbf{1 8 2}$ & $\mathbf{8} \%$ & $\mathbf{8 1} \%$ & $\mathbf{1 2} \%$ \\
\hline
\end{tabular}

Table 1: Table summarizing the mineral occurrency LVS; Halite and HVS) among several fields projects in the Santos Basin. Adapted from Maul et al. (2018a,b).

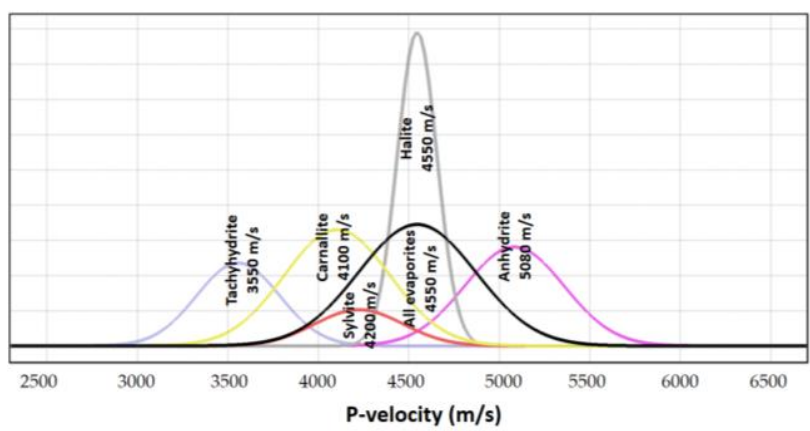

Figure 2: Mineral velocity variation obtained from the logs considering a piece (around 10 wells) among the 182 ones mentioned in Figure 1.

Adapted from Maul et al. (2018a). 

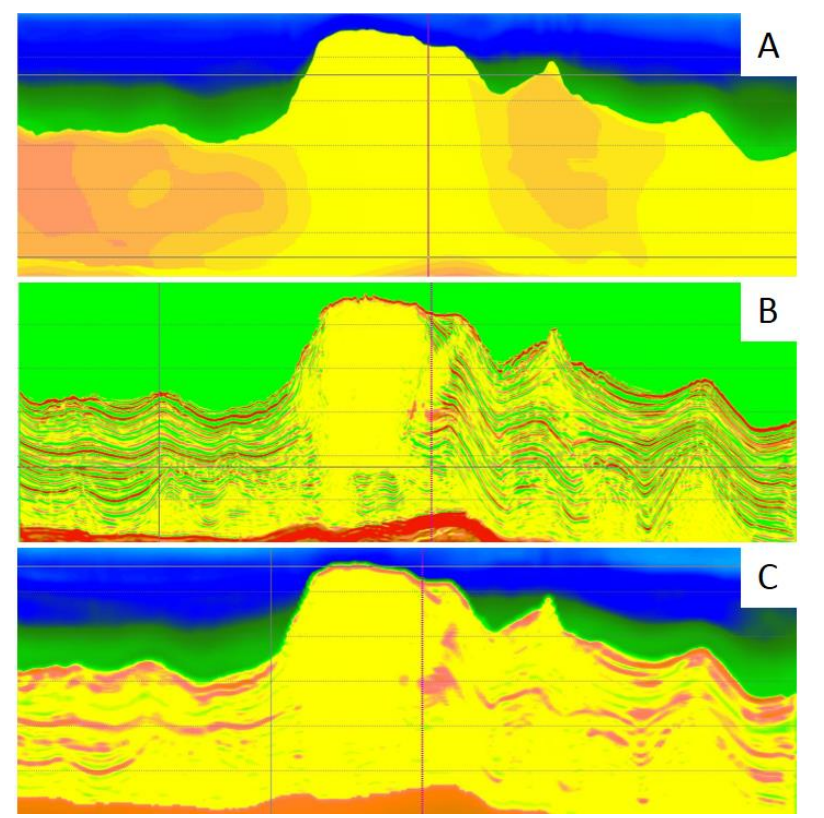

Figure 3: Salt heterogeneity representation:

$A \rightarrow$ Needed inversion tomography iteration to correct the almost constant interval velocity model using the gather alignment as criteria-control;

$B \rightarrow$ Seismic acoustic inversion results (model-based approach) illustrating the existing stratification controlled by the amplitude response and for the well information;

$C \rightarrow$ Interval velocity model obtained from the inversion results (in this case, after applying a polynomial transformation guided by the well logs, we smoothed the model vertically.

Adapted from Yamamoto et al. (2018) in Maul et al. (2018a).
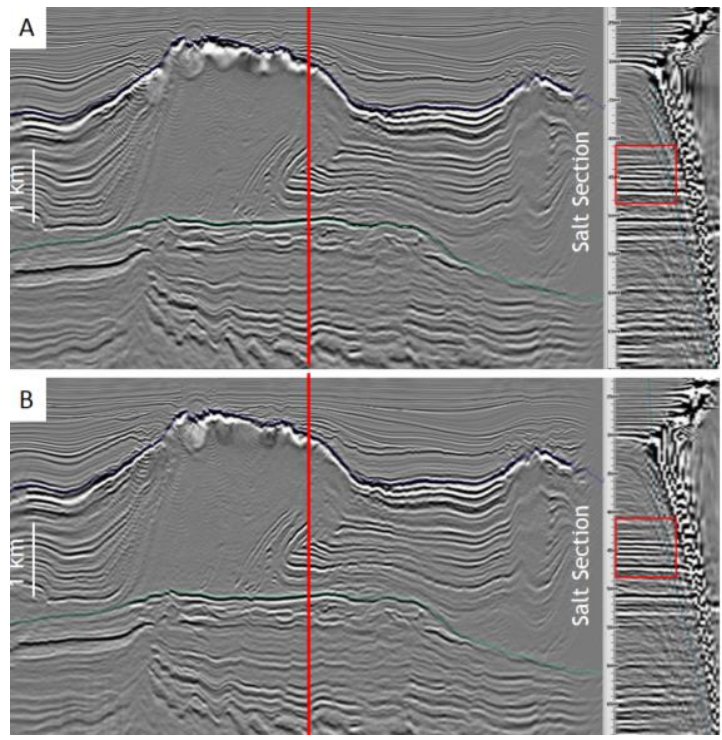

Figure 4: Migrated seismic section and a piece of a seismic gather panel illustrating the obtained alignment considering:

$A \rightarrow$ The starting velocity model almost constant after three tomographic inversion iterations;

$B \rightarrow$ The staring velocity model delivered by the stratification insertion after one tomographic inversion iteration.

Observe the same level of gather alignment in both examples, which implies in a reduction of computational cost when considering the stratified model.

Adapted from Maul et al. (2018a).
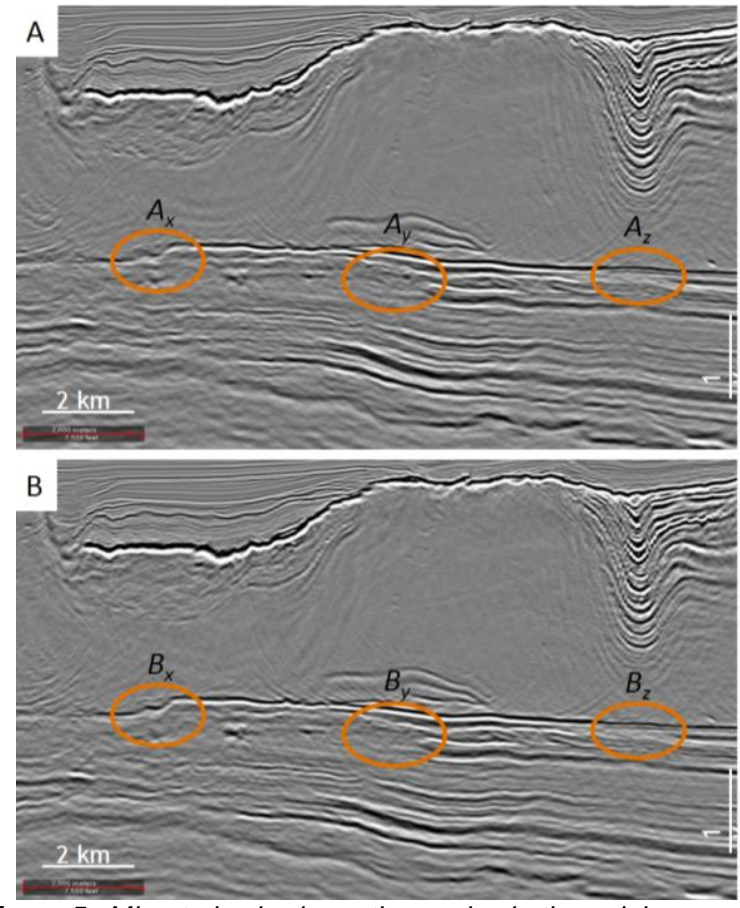

Figure 5: Migrated seismic sections using both models:

$A \rightarrow$ The starting velocity model almost constant after three tomographic inversion iterations;

$B \rightarrow$ The starting velocity model delivered by the stratification insertion after one tomographic inversion iteration.

Observe the better imaging when using the model with the stratification insertion (positions Bx over $A x$ and $B y$ over $B x$ ) and the vertical more coherent positioning in $B z$ than $A z$ (in this part it important to notice the salt behavior above the analyzed point!) Adapted from Maul et al. (2018a)

\section{Conclusions}

To improve seismic images in complex areas such as for the Pre-Salt reservoir in Santos Basin the chosen migration algorithm plus the more feasible interval velocity model containing the reliable geology features seems to be mandatory.

The insertion of the existing evaporitic stratifications using the model-based acoustic inversion approach is a reality, giving to the "salt section" an important contribution in terms of geology and the related property such as the needed starting interval velocity for any updating technique (tomography, FWI). By using this methodology, the computation effort decrease as we reduce number of iteration intending to get the gather alignment prior to the final migration process.

Despite this computational effort decreasing the most important statement when applying this combined approach (to perform the velocity update over the stratified salt model plus the good migration algorithm) delivers more reliable seismic images covering several aspects: better representation of structures, geological events continuity, depth predictions, signal quality, etc.

We still believe the anisotropic considerations, if needed for the salt section, could also consider this stratified model as the initial one. 
We tested this methodology in several projects driven to the seismic processing. Beyond this processing process, we also tested those models for seismic design (illumination studies), uncertainty analysis, security in well drilling, geomechanical flow simulation, etc. Therefore, despite matters related to any seismic ambiguity, seismic resolution, we do believe it is an approach to consider in all projects for the Pre-Salt section.

It also important to take care about other relevant aspects in terms of velocity model building not only for the salt section as described in this paper. Our group is also researching and applying similar methodologies, in this case, reflecting the needed geology reflected into the velocity models, such as the Albian rafts in Santos and Campos Basins, to insert structural complexity (folds and faults), etc.

\section{Acknowledgments}

The authors would like to thank Petrobras and Emerson for giving the support, time and data for this research, as well as for allowing the publication.

\section{References}

Fonseca J., Teixeira L., Maul A., Barros P., Boechat J. \& González M. 2018. Modelling geological layers into new velocity models for seismic migration process: A Brazilian Pre-Salt Case. First EAGE/PESGB Workshop on Velocities. London, UK. doi: 10.3997/22144609.201800010.

Gobatto F., Maul A., Falcão L., Teixeira L., Boechat J., González M. \& González G. 2016. Refining Velocity Model within the Salt Section in Santos Basin: an Innovative Workflow to include the Existing Stratification and its Considerations. SEG. $86^{\text {th }}$ Annual Meeting. Dallas, TX, USA. pp. 5328-5331. doi: 10.1190/segam201613685489.1.

González, M., Gobatto, F., Maul, A., Falcão, L., González, G., Oliveira, L., Meneguim, T. \& Amaral, P. J. 2016. Proposed Workflow to Incorporate Stratification within Salt Section using Velocity and Seismic Attributes. Third EAGE/SBGf Workshop on Quantitative Seismic Interpretation of Lacustrine Carbonates. Rio de Janeiro, RJ, Brazil. doi: 10.3997/22144609.201600050.

Guo, N. \& Fagin, S. 2002. Becoming Effective Velocity Model Builders and Depth Imagers, Part 2. The Basics of Velocity-Model Building, Examples and Discussions. The Leading Edge, v.21, n.12, p 1210-1216.

Jackson, C.A.-L., Jackson, M.P.A., Hudec, M.R. \& Rodriguez, C.R. 2015. Enigmatic Structures within Salt Walls of Santos Basin. Part 1: Geometry and Kinematics from 3D Seismic Reflection and Well Data. Journal of Structural Geology. 75, 135-162. doi: 10.1016/j.jsg.2015.01.010.

Jardim F., Maul A., Falcão L., \& González G. 2015. Estimating Amplitude Uncertainties through Illumination Studies for a Pre-Salt Reservoir. 14 ${ }^{\text {th }}$ International Congress of the SBGf. Rio de Janeiro, RJ, Brazil. doi: 10.1190/sbgf2015-160.
Ji, S., Huang, T. Fu, K. \& Li, Z. 2011. Dirty Salt Velocity Inversion: the Road to a Clearer Subsalt Image, Geophysics. 76(5). doi.org/10.1190/1.3513718.

Jones, I.F. \& Davison I. 2013. Seismic Imaging and Around Salt Bodies: Problems and Pitfalls. $75^{\text {th }}$ EAGE Conference \& Exhibition. London, UK. doi: 10.1190/segam20140047.1.

Jones, I.F. \& Davison I. 2014. Seismic Imaging in and around Salt Bodies. Interpretation. Vol.2, No.4, SL1SL20. doi: 10.1190/INT-2014-0033.1.

Maul A., Fonseca J., Teixeira L., Barros P., Boechat J., Nunes J.P., Yamamoto T., González M. \& González G. 2018a. Modelling Intra-Salt Layers when Building Velocity Models for Depth Migration. Examples of the Santos Basins, Brazilian Offshore. $88^{\text {th }}$ Annual Meeting. Anaheim, CA, USA. pp. 3764-3767. doi: 10.1190/segam2018-2996209.1.

Maul A., Jardim F., Falcão L., \& González G. 2015. Observing Amplitude Uncertainties for a PreSalt Reservoir Using Illumination Study (Hit-Maps). $77^{\text {th }}$ EAGE Conference \& Exhibition. Madrid, Spain. doi: 10.3997/2214-4609.201412921.

Maul A., Santos M. C. \& Silva, C. G. 2018b. Few Considerations, Warnings and Benefits for the E\&P Industry when Incorporating Stratification inside Salt Section. Revista Brasileira de Geofísica (RBGf), V.36, n.4. doi: 10.22564/rbgf.v36i4.1981.

Meneguim T., Mendes S.C., Maul A., Falcão L., González M. \& González G. 2015. Combining Seismic Facies Analysis and Well Information to Guide New Interval Velocity Models for a Pre-Salt Study, Santos Basin, Brazil. 14 ${ }^{\text {th }}$ International Congress of the SBGf. Rio de Janeiro, RJ, Brazil. doi: 10.1190/sbgf2015-271.

Mohriak, W., Nemcok, M. \& Enciso, G. 2008. South Atlantic Divergent Margin Evolution: Rift-Border Uplift and Salt Tectonics in the Basins of SE Brazil. Geological Society London Special Publications. January 2008. doi: 10.1144/SP294.19.

Teixeira L., Nunes J.P., Fonseca, J., Maul A., Barros P. \& Borges F. 2018. Seismic-Based Salt Characterisation for Geomechanical Modelling of a PreSalt Reservoir. 80 ${ }^{\text {th }}$ EAGE Conference \& Exhibition. Copenhagen, Denmark. doi: 10.3997/22144609.201801331.

Toríbio T., Queiroz L.E., Teixeira L., Yamamoto T., Meneguim T., Leonardi O., Cortez M., Relvas M.T., Moliterno, A.M., Tartarini A., Fonseca, J. \& Maul, A. 2017. Characterizing Evaporitic Section and Geomechanical Properties Using Seismic Inversion, a Case Study for Santos Basin. 15 $5^{\text {th }}$ International Congress of the SBGf. Rio de Janeiro, RJ, Brazil. doi: 10.1190/sbgf2017-226.

Vigh, D. \& Starr, E.W. 2008. 3D Pre-Stack Plane-Wave, Full WaveForm Inversion, Geophysics, Vol. 73, No. 5 (September-October, 2008).

Vigh, D., Starr, E.W. \& Dingwall, K. 2009. 3D Pre-Stack Full WaveForm Inversion, OTC (Offshore Technology Conference), Houston, Texas, USA (OTC 19897). 